\title{
Chronic Administration of a Combination of Six Herbs Inhibits the Progression of Hyperglycemia and Decreases Serum Lipids and Aspartate Amino Transferase Activity in Diabetic Rats
}

\author{
Reza Shafiee-Nick, ${ }^{1,2}$ Ahmad Ghorbani, ${ }^{1}$ \\ Farzaneh Vafaee Bagheri, ${ }^{1}$ and Hassan Rakhshandeh ${ }^{1,2}$ \\ ${ }^{1}$ Pharmacological Research Center of Medicinal Plants, School of Medicine, Mashhad University of Medical Sciences, \\ Mashhad 9177948564, Iran \\ ${ }^{2}$ Department of Pharmacology, School of Medicine, Mashhad University of Medical Sciences, Mashhad 9177948564, Iran \\ Correspondence should be addressed to Ahmad Ghorbani, ghorbania@mums.ac.ir
}

Received 31 July 2012; Revised 15 October 2012; Accepted 29 October 2012

Academic Editor: Owen L. Woodman

Copyright $\odot 2012$ Reza Shafiee-Nick et al. This is an open access article distributed under the Creative Commons Attribution License, which permits unrestricted use, distribution, and reproduction in any medium, provided the original work is properly cited.

\begin{abstract}
The effects of a polyherbal compound, containing six plants (Allium sativum, Cinnamomum zeylanicum, Nigella sativa, Punica granatum, Salvia officinalis and Teucrium polium) were tested on biochemical parameters in streptozotocin-induced diabetic rats. Streptozotocin caused an approximately 3 -fold increase in fasting blood sugar level after 2 days. The diabetic control rats showed further increase in blood glucose after 30 days $(384 \pm 25 \mathrm{mg} / \mathrm{dl}$ in day 30 versus $280 \pm 12 \mathrm{mg} / \mathrm{dl}$ in day $2, P<0.001)$. Administration of the compound blocked the increase of blood glucose $(272 \pm 7$ and $269 \pm 48 \mathrm{mg} / \mathrm{dl}$ at day 2 and day 30 , respectively). Also, there was significant difference in the level of triglyceride ( $60 \pm 9$ versus $158 \pm 37 \mathrm{mg} / \mathrm{dl}, P<0.01)$, total cholesterol (55 \pm 2 versus $97 \pm 11 \mathrm{mg} / \mathrm{dl}, \mathrm{P}<0.01)$ and aspartate amino transferase activity $(75 \pm 12$ versus $129 \pm 18 \mathrm{U} / \mathrm{L}, P<0.05)$ between treated rats and diabetic control group. In conclusion, the MSEC inhibited the progression of hyperglycemia and decreased serum lipids and hepatic enzyme activity in diabetic rats. Therefore, it has the potential to be used as a natural product for the management of diabetes.
\end{abstract}

\section{Introduction}

Diabetes mellitus, a metabolic disease with manifestation of hyperglycemia, is a fast growing health problem through out the world. The World Health Organization estimates that 346 million people suffer from diabetes worldwide. Without urgent action, this number is likely to double by 2030. Generally, diabetes is classified into two main types: type-1 diabetes, a state of insulin deficiency because of defect in islet $\beta$-cell function and type- 2 diabetes which mainly characterized by resistance to the actions of insulin. Over time, diabetes leads to serious microvascular and macrovascular complications such as nephropathy, retinopathy, neuropathy, and cardiovascular disease [1]. Although early onset manifestations of diabetes can be controlled by current oral hypoglycemic drugs or insulin treatment, serious late onset complications appear in many patients [2]. Moreover, the hypoglycemic drugs lead to some unpleasant side effects such as lactic acidosis, peripheral edema, severe hypoglycemia, and abdominal discomfort [3]. Therefore, the search for new antidiabetic agents has continued.

Plants have always been a good source for finding new therapeutic agents for human diseases. Antidiabetic effects of several plants have been supported by results from animal models and clinical trials $[4,5]$. Among them, Allium sativum, Cinnamomum zeylanicum, Nigella sativa, Punica granatum, Salvia officinalis, and Teucrium polium are widely used as medicinal plants for management of diabetes in Middle East [6, 7]. Recently, several studies have shown that each one of the six plants is effective in decrease of plasma glucose and serum lipids in diabetes [8-18]. We hypothesized that a combination of their extracts may have more effect 
TABLE 1: Composition of polyherbal compounds.

\begin{tabular}{lccc}
\hline \multirow{2}{*}{ Herbs } & \multicolumn{3}{c}{ Quantity (g/100 g of compound) } \\
& MEC & SEC & MSEC (MEC + SEC) \\
\hline Allium sativum & 16 & 16 & $8+8$ \\
Cinnamomum zeylanicum & 14 & 14 & $7+7$ \\
Nigella sativa & 28 & 28 & $14+14$ \\
Punica granatum & 14 & 14 & $7+7$ \\
Salvia officinalis & 14 & 14 & $7+7$ \\
Teucrium polium & 14 & 14 & $7+7$ \\
\hline
\end{tabular}

MEC: macerated extracts compound; SEC: Soxhlet extracts compound; MSEC: combination of both MEC and SEC.

on improving metabolic indexes in diabetes. Therefore, the present work was carried out to investigate antidiabetic activity of a polyherbal compound containing these six plant species.

\section{Materials and Methods}

2.1. Preparation of Extracts. The air-dried A. sativum (cloves), C. zeylanicum (bark), N. sativa (seeds), P. granatum (fruits), S. officinalis (areal parts), and T. polium (areal parts) were powdered and used for extraction. For each plant two types of hydroalcoholic extract were prepared: macerated extract (ME) and Soxhlet extract (SE). The ME was prepared by suspension of each powdered plant material in $70 \%$ ethanol and incubated for $72 \mathrm{~h}$ at $37^{\circ} \mathrm{C}$. The SE was made in a Soxhlet apparatus with $70 \%$ ethanol for $24 \mathrm{~h}[19,20]$. The ME and SE of each plant were evaporated to dryness and then mixed as indicated in Table 1 to make three test compounds: MEs compound (MEC), SEs compound (SEC) and a combination of both MEC and SEC (MSEC).

2.2. Animals. Male albino Wistar rats (280-330 g) were used for each experiment. They were housed in a room with controlled lighting ( $12 \mathrm{~h}$ light/12 h darkness) and temperature $\left(22 \pm 2^{\circ} \mathrm{C}\right)$. The animals were given standard pellets diet and water ad libitum. The study protocol using laboratory animals complied with the guidelines of the animal care of the Mashhad University of Medical Sciences, Mashhad, Iran.

2.3. Induction of Diabetes. The animals were given a single dose $(55 \mathrm{mg} / \mathrm{kg}$, ip) of streptozotocin (STZ) (Enzo Life, USA). Development of diabetes was confirmed by measuring fasting blood sugar (FBS) two days after STZ injection $[21,22]$. Rats with FBS level of $250 \mathrm{mg} / \mathrm{kg}$ or higher were considered to be diabetic.

2.4. Glucose Tolerance Test. Oral glucose tolerance test (GTT) was performed on normal rats that were fasted $16 \mathrm{~h}$. The animals were divided into 4 groups comprising of 8 animals in each groups. The rats in group 1, 2, 3, and 4 were received vehicle, MEC ( $1 \mathrm{~g} / \mathrm{kg})$, SEC ( $1 \mathrm{~g} / \mathrm{kg})$, and glibenclamide ( $1 \mathrm{mg} / \mathrm{kg}$ ), respectively. The vehicle or test compounds were given orally thirty minutes before administration of glucose $(2 \mathrm{~g} / \mathrm{kg})$. A fasting blood sample was first collected from

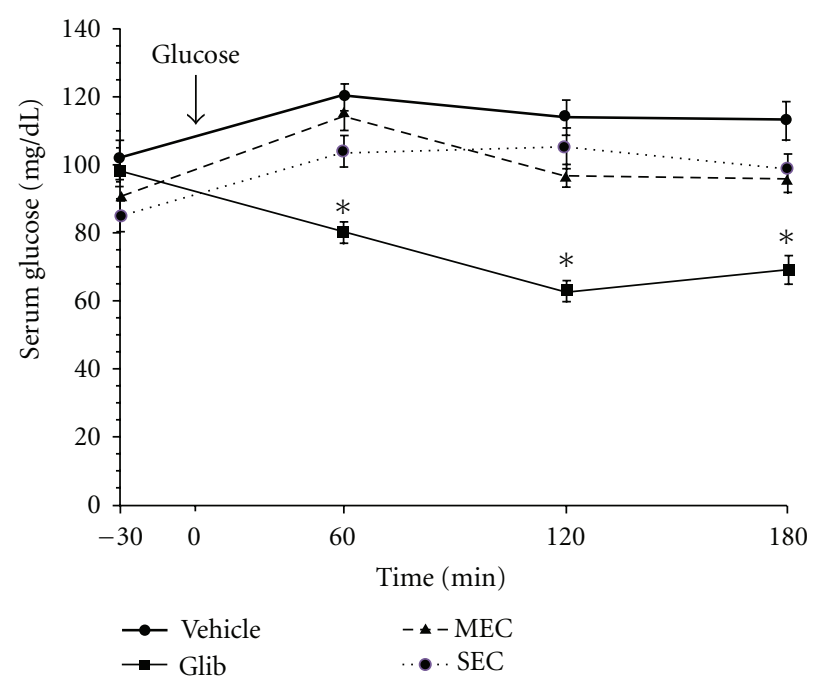

FIGURE 1: Effect of test compounds on glucose tolerance test (GTT) in normal rats. After $16 \mathrm{~h}$ fasting, the animals were received water as vehicle, glibenclamide $(1 \mathrm{mg} / \mathrm{kg})$, or test compounds $(1 \mathrm{~g} / \mathrm{kg})$ orally thirty minutes before administration of glucose $(2 \mathrm{~g} / \mathrm{kg})$. The data are expressed as mean $\pm \operatorname{SEM}(n=8) .{ }^{*} P<0.01$ compared with the corresponding values at all other groups. Glib: glibenclamide-MEC: macerated extracts compound; SEC: Soxhlet extracts compound.

retroorbital sinus, and then three more samples were taken at the 60,120 , and $180 \mathrm{~min}$ intervals following glucose administration.

2.5. Long-Term Administration of Test Compounds. Diabetic rats were randomized into two groups, 7 animals each: (1) diabetic control rats which were fed standard pellets diet, and (2) diabetic rats which were received diet containing $4 \%(\mathrm{w} / \mathrm{w})$ of MSEC. The treatment was initiated two days after STZ injection and continued for 4 weeks. At the end of the 30th day, the rats were fasted $16 \mathrm{~h}$ and blood samples were collected from retroorbital sinus for biochemical measurements. Also, a $2 \mathrm{~h}$ glucose tolerance assay was conducted in the 30th day.

2.6. Biochemical Assays. Blood glucose was measured using glucose oxidase reagent (Ziest Chem Diagnostics, Iran). Total cholesterol and high-density lipoprotein (HDL) were evaluated with standard enzymatic colorimetric kits from Pars Azmun (Iran). Serum triglyceride was measured using an enzymatic colorimetric test (Ziest Chem Diagnostics, Iran). Serum alanine aminotransferase (ALT) and aspartate aminotransferase (AST) activities were measured colorimetrically by commercially available kits (Pars Azmun, Iran).

2.7. Statistical Analysis. Statistical analysis of changes from baseline was performed by paired t-test within groups. Intergroup comparison was done by one-way ANOVA with Turkey's post-hoc test. Results showing $P$ values less than 0.05 were considered significant. 
TABLE 2: Effect of long-term administration of MSEC on blood glucose level in diabetic rats.

\begin{tabular}{lcccc}
\hline \multirow{2}{*}{ Animal groups } & \multicolumn{3}{c}{ Blood glucose (mg/dL) } \\
& Day 0 (FBS) & Day 2 (FBS) & Day 30 (FBS) & Day 30 (2 h GTT) \\
\hline Normal control & $85 \pm 5$ & $82 \pm 6$ & $86 \pm 8$ & $115 \pm 6^{\#}$ \\
Diabetic control & $91 \pm 5$ & $280 \pm 12^{*}$ & $384 \pm 25^{* \dagger}$ & $451 \pm 26^{*}$ \\
Diabetic + MSEC & $96 \pm 4$ & $272 \pm 7^{*}$ & $269 \pm 48^{*}$ & $347 \pm 29^{*}$ \\
\hline
\end{tabular}

The data are expressed as mean \pm SEM $(n=7) .{ }^{*} P<0.001$ compared with the corresponding values at day 0 in each group. ${ }^{\#} P<0.05$ compared with FBS value at day 30 for normal control group. ${ }^{\dagger} P<0.05$ compared with the corresponding values at day 2 for Diabetic control group. FBS: fasting blood sugar; MSEC: combination of both macerated and Soxhlet extracts (see Table 1); GTT: glucose tolerance test.

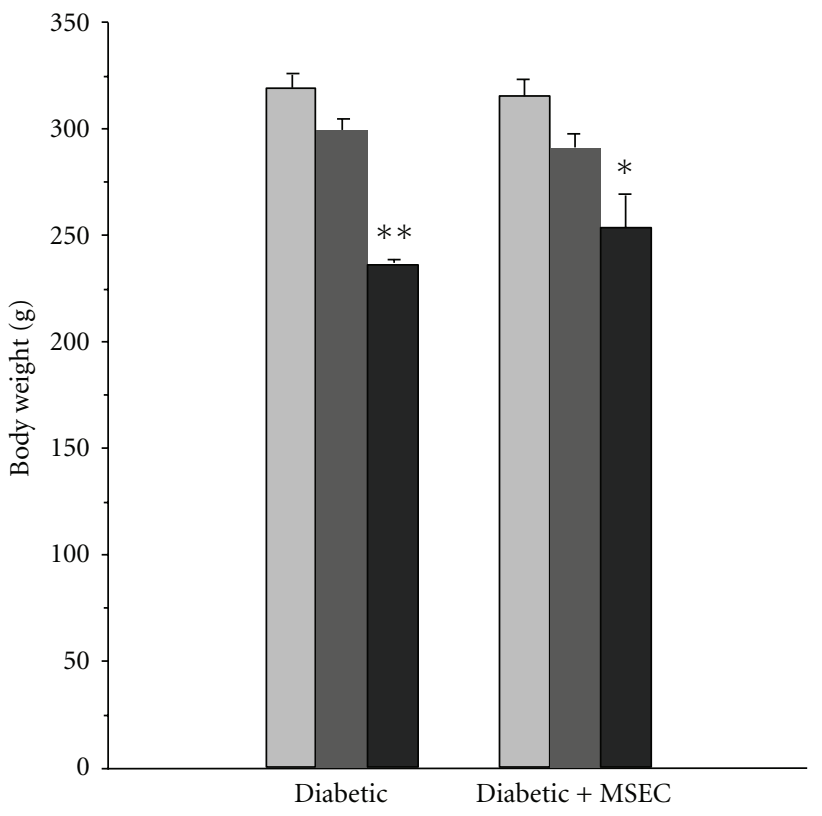

$$
\begin{aligned}
& \text { Day } 0 \\
& \text { Day } 2 \\
& \text { Day } 30
\end{aligned}
$$

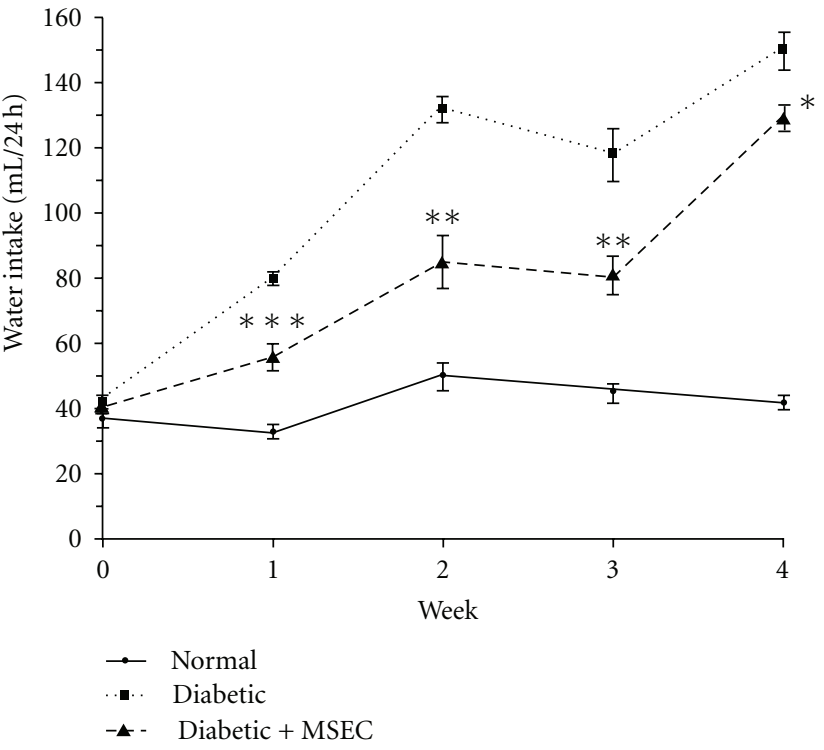

(b)

FIGURE 2: Effect of long-term administration of MSEC on body weight and water intakein diabetic rats. The animals in group of diabetic + MSEC received diet containing 4\% (w/w) of MSEC for 1 month. (a): ${ }^{*} P<0.01$ compared with the corresponding values at day 2 and day $0 .{ }^{* *} P<0.001$ compared with the corresponding values at day 2 or day 0 . (b): ${ }^{*} P<0.001$ and $P<0.05$ compared with the corresponding values of normal and diabetic + MSEC group, respectively. ${ }^{* *} P<0.01$ compared with the corresponding values of normal or diabetic + MSEC group. ${ }^{* * *} P<0.001$ compared with the corresponding values of normal or diabetic + MSEC group. The data are expressed as mean \pm SEM for seven (body weight) or six (water intake) rats. MSEC: combination of both macerated and Soxhlet extracts (see Table 1).

\section{Results}

3.1. Effect of Test Compounds on Glucose Tolerance. Results of GTT conducted on normal rats are shown in Figure 1. The plasma glucose levels of the control rats reached a peak at $60 \mathrm{~min}$ after administration of glucose and gradually decreased. The glibenclamide produced plasma glucose levels significantly $(P<0.001)$ lower than those of the control group at 60-120 min after the glucose administration. When the basal glucose levels were adjusted to $100 \%$, neither the MEC nor the SEC showed significant effect on serum glucose at 60,120 , or $180 \mathrm{~min}$ as compared to those of the control group.

3.2. Effect of MSEC on Blood Glucose. As shown in Table 2, prior to STZ injection, FBS levels of all the groups were not statistically different from each other. At day 2, administration of STZ to rats caused an approximately 3 -fold increase in FBS level compared to normal controls. The diabetic control rats showed further increase in FBS level after 30 days $(384 \pm 25 \mathrm{mg} / \mathrm{dL}$ in day 30 versus $280 \pm 12 \mathrm{mg} / \mathrm{dL}$ in day 2 , 


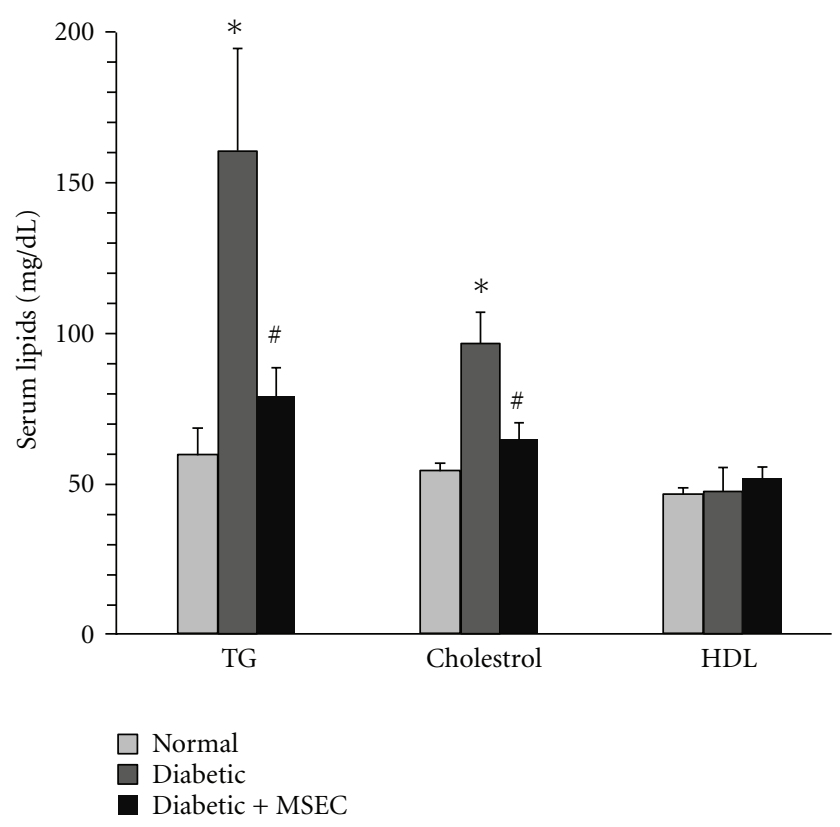

FIGURE 3: Effect of long-term administration of MSEC on the levels of plasma lipids in diabetic rats. The animals in group of diabetic + MSEC received diet containing $4 \%(\mathrm{w} / \mathrm{w})$ of MSEC for 1 month. ${ }^{*} P<0.01$ versus normal rats. ${ }^{\#} P<0.05$ versus diabetic group. The data are expressed as mean \pm SEM for eight (normal and diabetic + MSEC groups) or six (diabetic groups) rats. MSEC: combination of both macerated and Soxhlet extracts; TG: triglycerides; TC: total cholesterol; HDL: high-density lipoprotein.

$P<0.001)$. However, administration of MSEC to diabetic rats blocked the increase of blood glucose. The level of FBS in this group was $272 \pm 7$ and $269 \pm 48 \mathrm{mg} / \mathrm{dL}$ at day 2 and day 30 , respectively.

Two hours after feeding of glucose, the blood sugar rose to $451 \pm 26 \mathrm{mg} / \mathrm{dL}$ from $384 \pm 25 \mathrm{mg} / \mathrm{dL}$ and to $347 \pm 29 \mathrm{mg} / \mathrm{dL}$ from $269 \pm 48 \mathrm{mg} / \mathrm{dL}$ in the case of diabetic controls and MSEC-treated rats, respectively.

3.3. Effect of MSEC on Body Weight and Water Intake. After two daysof STZ injection, the diabetic rats in control and MSEC-treated groups showed a significant reduction in their original body weight from $320 \pm 6$ to $300 \pm 5 \mathrm{~g}(P<0.01)$ and from $315 \pm 7$ to $292 \pm 6 \mathrm{~g}(P<0.01)$, respectively. The weight reduction was continued for both groups and at 30 th day reached to $236 \pm 4 \mathrm{~g}(P<0.01$ versus day 2$)$ and $254 \pm 16 \mathrm{~g}(P<0.05$ versus day 2$)$ for control and MSECtreated animals, respectively (Figure $2(\mathrm{a})$ ).

In all groups prior to diabetes induction, the levels of water intake were not significantly different. However, there was a significant increase in the levels of water intake in both groups of diabetic rats after STZ administration (Figure 2(b)). Although the polydipsia condition was evident from the first week to the end of the experiment period, the level of water intake in MSEC-treated rats was significantly lower than that of control diabetic group.

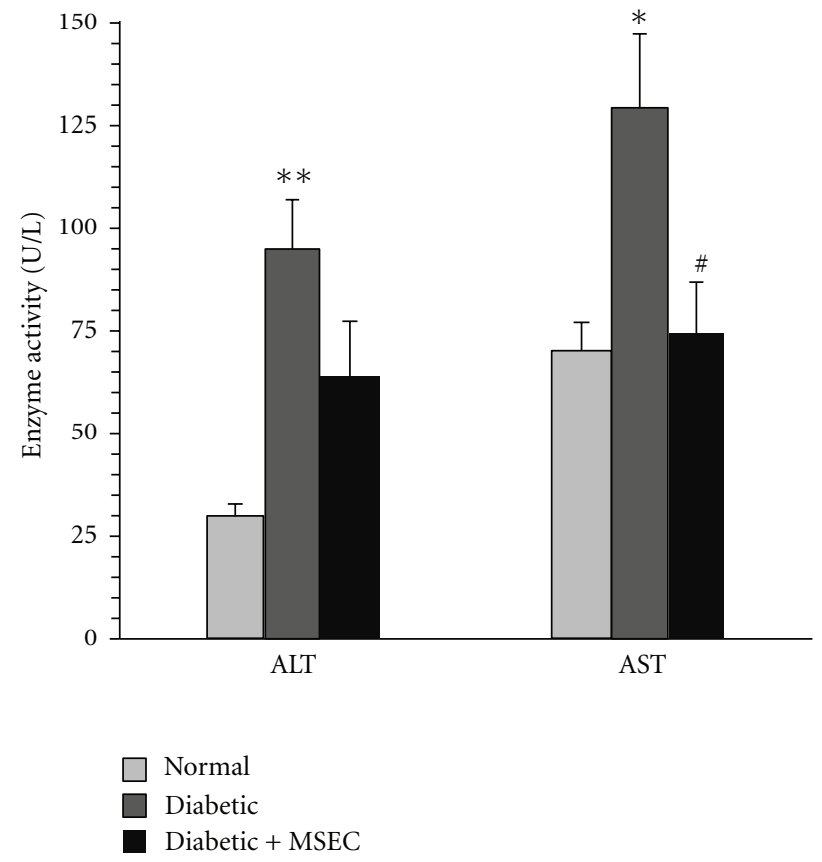

FIGURE 4: Effect of MSEC on serum alanine aminotransferase (ALT) and aspartate aminotransferase (AST) activities in diabetic rats. The animals in group of diabetic + MSEC received diet containing 4\% (w/w) of MSEC for 1 month. ${ }^{*} P<0.05$ versus normal and diabetic + MSEC groups. ${ }^{* *} P<0.01$ versus normal rats. ${ }^{\#} P<0.05$ versus diabetic group. The data are expressed as mean \pm SEM for eight (normal and diabetic + MSEC groups) or six (diabetic groups) rats. MSEC: combination of both macerated and Soxhlet extracts.

3.4. Effect of MSEC on the Levels of Serum Lipids. Figure 3 shows the effect of MSEC on serum lipids in diabetic rats. There was a significant elevation in the level of triglyceride $(60 \pm 9 \mathrm{mg} / \mathrm{dL}$ versus $158 \pm 37 \mathrm{mg} / \mathrm{dL}, P<0.01)$ and total cholesterol $(55 \pm 2 \mathrm{mg} / \mathrm{dL}$ versus $97 \pm 11 \mathrm{mg} / \mathrm{dL}, P<0.01)$ in diabetic rats as compared with normal rats. The MSEC was found to be effective in decreasing the serum lipids. The levels of triglyceride and total cholesterol in MSEC-treated group were $80 \pm 9 \mathrm{mg} / \mathrm{dL}(P<0.01$ versus the corresponding value of diabetic rats $)$ and $65 \pm 6 \mathrm{mg} / \mathrm{dL}(P<0.01$ versus the corresponding value of diabetic rats), respectively. There was no significant difference between the groups in serum HDL level.

3.5. Effect of MSEC on the Serum Enzyme Activity. After 30 days of diabetes induction, the activity of serum ALT was more than three times relative to the normal animals $(95 \pm 12$ versus $30 \pm 3 \mathrm{U} / \mathrm{L}, P<0.01)$. Similarly, diabetic rats showed higher AST activity than normal group $(129 \pm 18$ versus $70 \pm 7 \mathrm{U} / \mathrm{L}, P<0.05)$. Treatment with MSEC decreased the ALT activity $(64 \pm 13 \mathrm{U} / \mathrm{L})$; however, the effect was statistically insignificant (Figure 4). On the other hand, there was significant difference in the AST activity between MSECtreated rats $(75 \pm 12 \mathrm{U} / \mathrm{L}, P<0.05)$ and diabetic control group $(129 \pm 18 \mathrm{U} / \mathrm{L})$. 


\section{Discussion}

In the present study, we tested the possible beneficial effects of a polyherbal compound, containing six plants (A. sativum, C. zeylanicum, N. sativa, $P$. granatum, S. officinalis, and T. polium) on biochemical parameters of diabetic rats. Although this compound (MSEC) failed to completely restore STZ-induced hyperglycemia and had no remarkable effect on weight reduction; however, it significantly prevented further elevation of blood sugar and improved the polydipsia state. Therefore, it seems that administration of MSEC can only inhibit progression and deterioration of hyperglycemia. Additionally, normal rats treated with MEC or SEC did not change significantly the glycaemia values on GTT, which indicates an antihyperglycemic effect rather than a hypoglycaemic one for the constituents of MSEC. This effect is expected to happen as antihyperglycemic property of its herbal constituents (i.e., the six plants) has been confirmed with repeated studies [8-18].

Antihyperglycemic effect of plants is achieved by enhancing insulin secretion from beta cells, increasing glucose uptake by tissues, decreasing glucose absorption from intestine, inhibiting glucose production in liver, increasing pancreatic tissue regeneration [23], and/or presence of insulin-like agents in plants $[4,23,24]$. Recent studies have shown that $P$. granatum inhibits $\alpha$-glucosidase, ratelimiting enzymes for digestion of oligosaccharides which are necessary for intestinal absorption of glucose. Also, it has been demonstrated that $N$. sativa and S. officinalis decrease hepatic glucose production through inhibition of gluconeogenic enzymes. Moreover, beneficial effect of $T$. polium on regeneration of pancreatic islets was reported [2528].

The levels of serum triglyceride and cholesterol are usually elevated in diabetic patients [29]. The hyperlipidemia mainly occurs as a result of insulin deficiency and thereby dysregulation of metabolic processes like lipolysis and lipogenesis [30]. In the present study also, the diabetic animals showed hypertriglyceridemia, and hypercholesterolemia and the treatment with MSEC significantly decreased the hyperlipidemia. Therefore, the product most probably can prevent dyslipidemia-related complications of diabetic patients. The hypolipidemic action of MSEC is in agreement with earlier studies that reported that A. sativum, C. zeylanicum, $N$. sativa, S. officinalis, and T. polium decrease the levels of serum triglyceride and cholesterol in diabetic animals $[8,11,12,16$, $18]$.

Measurements of serum ALT and AST are used in the evaluation of liver damage. Elevation of these enzyme activities is considered as evidence for hepatic damage. An increase of these enzyme activities is also associated with fatty liver disease and decreased hepatic insulin sensitivity in type-2 diabetes $[31,32]$. Recently, it has shown that fatty liver disease is associated with an increased risk of death among diabetic patients [33]. In our study, recovery of serum ALT and AST activities of diabetic rats towards normal level shows that the MSEC has protective effect against liver damage and therefore can improve prognosis of diabetic patients. According to the results of previous studies, the main components responsible for this protective effect are most likely found in A. sativum, S. officinalis, and T. polium $[8,16,34]$.

In conclusion, the present study demonstrated that MSEC has antidiabetic actions mainly through its hypolipidemic and hepatoprotective effects as well as through inhibition of progression and deterioration of glycemia. Therefore, it has the potential to be used as a new natural product for the management of diabetes.

\section{Conflict of Interests}

The authors declare that they have no conflict of interests.

\section{Acknowledgments}

This work was supported by a grant from Research Council of Mashhad University of Medical Sciences, Mashhad, Iran.

\section{References}

[1] A. D. Deshpande, M. Harris-Hayes, and M. Schootman, "Epidemiology of diabetes and diabetes-related complications," Physical Therapy, vol. 88, no. 11, pp. 1254-1264, 2008.

[2] I. Tzoulaki, M. Molokhia, V. Curcin et al., "Risk of cardiovascular disease and all cause mortality among patients with type 2 diabetes prescribed oral antidiabetes drugs: retrospective cohort study using UK general practice research database," British Medical Journal, vol. 339, p. b4731, 2009.

[3] B. Lorenzati, C. Zucco, S. Miglietta, F. Lamberti, and G. Bruno, "Oral hypoglycemic drugs: pathophysiological basis of their mechanism of action," Pharmaceuticals, vol. 3, no. 9, pp. 30053020, 2010.

[4] H. Hui, G. Tang, and V. L. W. Go, "Hypoglycemic herbs and their action mechanisms," Chinese Medicine, vol. 4, no. 1, article 11, 2009.

[5] M. Modak, P. Dixit, J. Londhe, S. Ghaskadbi, and T. P. A. Devasagayam, "Indian herbs and herbal drugs used for the treatment of diabetes," Journal of Clinical Biochemistry and Nutrition, vol. 40, no. 3, pp. 163-173, 2007.

[6] A. Ghorbani and H. Rakhshandeh, The Most Effective Herbs for Diabetes, Mashhad University of Medical Sciences, Mashhad, Iran, 2012.

[7] S. Hasani-Ranjbar, B. Larijani, and M. Abdollah, "A systematic review of iranian medicinal plants useful in diabetes mellitus," Archives of Medical Science, vol. 4, no. 3, pp. 285-292, 2008.

[8] A. Eidi, M. Eidi, and E. Esmaeili, "Antidiabetic effect of garlic (Allium sativum L.) in normal and streptozotocin-induced diabetic rats," Phytomedicine, vol. 13, no. 9-10, pp. 624-629, 2006.

[9] F. M. El-Demerdash, M. I. Yousef, and N. I. Abou El-Naga, "Biochemical study on the hypoglycemic effects of onion and garlic in alloxan-induced diabetic rats," Food and Chemical Toxicology, vol. 43, no. 1, pp. 57-63, 2005.

[10] B. Mang, M. Wolters, B. Schmitt et al., "Effects of a cinnamon extract on plasma glucose, $\mathrm{HbA}_{1 c}$, and serum lipids in diabetes mellitus type 2," European Journal of Clinical Investigation, vol. 36, no. 5, pp. 340-344, 2006.

[11] S. A. Hassan, R. Barthwal, M. S. Nair, and S. S. Haque, "Aqueous bark extract of Cinnamomum Zeylanicum: a potential therapeutic agent for streptozotocin-induced type 1 diabetes 
mellitus (T1DM) rats," Tropical Journal of Pharmaceutical Research, vol. 13, no. 3, pp. 429-435, 2012.

[12] M. Kaleem, D. Kirmani, M. Asif, Q. Ahmed, and B. Bano, "Biochemical effects of Nigella sativa L seeds in diabetic rats," Indian Journal of Experimental Biology, vol. 44, no. 9, pp. 745748, 2006.

[13] I. Meral, Z. Yener, T. Kahraman, and N. Mert, "Effect of Nigella sativa on glucose concentration, lipid peroxidation, antioxidant defence system and liver damage in experimentallyinduced diabetic rabbits," Journal of Veterinary Medicine A, vol. 48, no. 10, pp. 593-599, 2001.

[14] A. Esmaillzadeh, F. Tahbaz, I. Gaieni, H. Alavi-Majd, and L. Azadbakht, "Cholesterol-lowering effect of concentrated pomegranate juice consumption in type II diabetic patients with hyperlipidemia," International Journal for Vitamin and Nutrition Research, vol. 76, no. 3, pp. 147-151, 2006.

[15] M. A. Jafri, M. Aslam, K. Javed, and S. Singh, "Effect of Punica granatum Linn. (flowers) on blood glucose level in normal and alloxan-induced diabetic rats," Journal of Ethnopharmacology, vol. 70, no. 3, pp. 309-314, 2000.

[16] A. Eidi and M. Eidi, "Antidiabetic effects of sage (Salvia officinalis L.) leaves in normal and streptozotocin-induced diabetic rats," Diabetes \& Metabolic Syndrome, vol. 3, no. 1, pp. 40-44, 2009.

[17] M. R. Shahraki, M. R. Arab, E. Mirimokaddam, and M. J. Palan, "The effect of Teucrium polium (Calpoureh) on liver function, serum lipids and glucose in diabetic male rats," Iranian Biomedical Journal, vol. 11, no. 1, pp. 65-68, 2007.

[18] F. Karimi, S. Abbasi, and A. R. Bateni, "The effect of Teucrium polium on blood glucose in diabetes mellitus type 2; a comparison with glibenclamide," Iranian South Medical Journal, vol. 2, no. 2, pp. 96-103, 2002.

[19] S. M. Mortazavian and A. Ghorbani, "Antiproliferative effect of Viola tricolor on neuroblastoma cells in vitro," Australian Journal of Medicinal Herbalism, vol. 24, no. 3, pp. 93-96, 2012.

[20] A. Ghorbani, N. J. Youssofabad, and H. Rakhshandeh, "Effect of Viola tricolor on pentobarbital-induced sleep in mice," African Journal of Pharmacy and Pharmacology, vol. 6, no. 33, pp. 2503-2509, 2012.

[21] A. Ghorbani, M. Varedi, M. A. R. Hadjzadeh, and G. H. Omrani, "Type-1 diabetes induces depot-specific alterations in adipocyte diameter and mass of adipose tissues in the rat," Experimental and Clinical Endocrinology and Diabetes, vol. 118, no. 7, pp. 442-448, 2010.

[22] A. Ghorbani, G. H. Omrani, M. R. Hadjzadeh, and M. Varedi, "Proinsulin C-peptide inhibits lipolysis in diabetic rat adipose tissue through phosphodiestrase-3Benzyme," Hormone and Metabolic Research. In press.

[23] K. R. Shanmugasundaram, C. Panneerselvam, P. Samudram, and E. R. B. Shanmugasundaram, "The insulinotropic activity of Gymnema sylvestre, R. Br. an Indian medical herb used in controlling diabetes mellitus," Pharmacological Research Communications, vol. 13, no. 5, pp. 475-486, 1981.

[24] A. M. Gray and P. R. Flatt, "Insulin-releasing and insulinlike activity of the traditional anti-diabetic plant Coriandrum sativum (coriander)," British Journal of Nutrition, vol. 81, no. 3, pp. 203-209, 1999.

[25] L. Pari and C. Sankaranarayanan, "Beneficial effects of thymoquinone on hepatic key enzymes in streptozotocinnicotinamide induced diabetic rats," Life Sciences, vol. 85, no. 23-26, pp. 830-834, 2009.
[26] K. M. Fararh, Y. Atoji, Y. Shimizu, and T. Takewaki, "Isulinotropic properties of Nigella sativa oil in Streptozotocin plus Nicotinamide diabetic hamster," Research in Veterinary Science, vol. 73, no. 3, pp. 279-282, 2002.

[27] C. F. Lima, M. F. Azevedo, R. Araujo, M. Fernandes-Ferreira, and C. Pereira-Wilson, "Metformin-like effect of Salvia officinalis (common sage): is it useful in diabetes prevention?" British Journal of Nutrition, vol. 96, no. 2, pp. 326-333, 2006.

[28] M. Vessal, F. Zal, and M. Vasei, "Effects of Teucrium polium on oral glucose tolerance test, regeneration of pancreatic islets and activity of hepatic glucokinase in diabetic rats," Archives of Iranian Medicine, vol. 6, no. 1, pp. 35-39, 2003.

[29] J. Patel, "Diabetes: managing dyslipidaemia," Clinical Evidence, vol. 2008, p. 0610, 2008.

[30] P. Arner, "Human fat cell lipolysis: biochemistry, regulation and clinical role," Best Practice \& Research Clinical Endocrinology \& Metabolism, vol. 19, no. 4, pp. 471-482, 2005.

[31] R. K. Schindhelm, M. Diamant, J. M. Dekker, M. E. Tushuizen, T. Teerlink, and R. J. Heine, "Alanine aminotransferase as a marker of non-alcoholic fatty liver disease in relation to type 2 diabetes mellitus and cardiovascular disease," Diabetes/Metabolism Research and Reviews, vol. 22, no. 6, pp. 437443, 2006.

[32] B. Vozarova, N. Stefan, R. S. Lindsay et al., "High alanine aminotransferase is associated with decreased hepatic insulin sensitivity and predicts the development of type 2 diabetes," Diabetes, vol. 51, no. 6, pp. 1889-1895, 2002.

[33] L. A. Adams, S. Harmsen, J. L. S. Sauver et al., "Nonalcoholic fatty liver disease increases risk of death among patients with diabetes: a community-based cohort study," American Journal of Gastroenterology, vol. 105, no. 7, pp. 1567-1573, 2010.

[34] S. Shtukmaster, P. Ljubuncic, and A. Bomzon, "The effect of an aqueous extract of Teucrium polium on glutathione homeostasis in vitro: a possible mechanism of its hepatoprotectant action," Advances in Pharmacological Sciences, vol. 2010, Article ID 938324, 7 pages, 2010. 

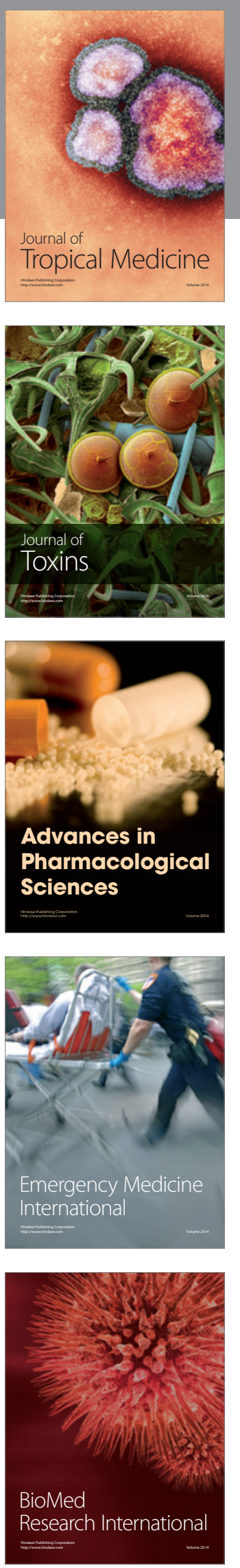
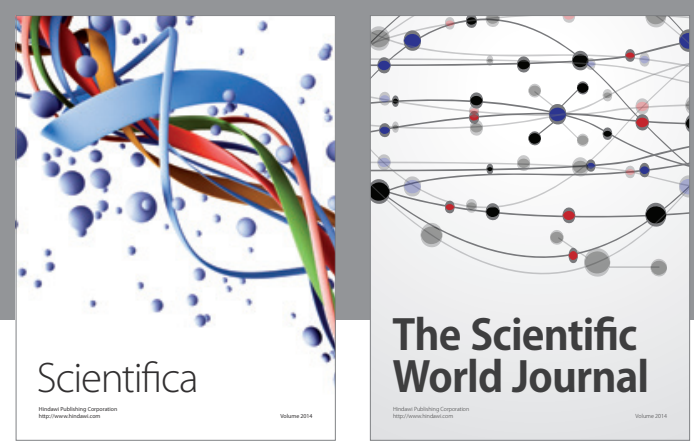

The Scientific World Journal
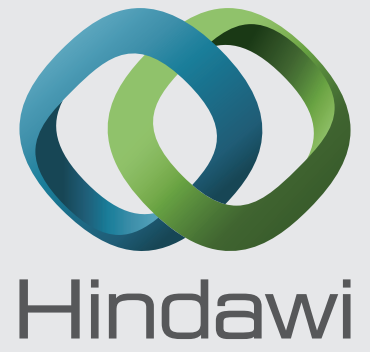

Submit your manuscripts at

http://www.hindawi.com
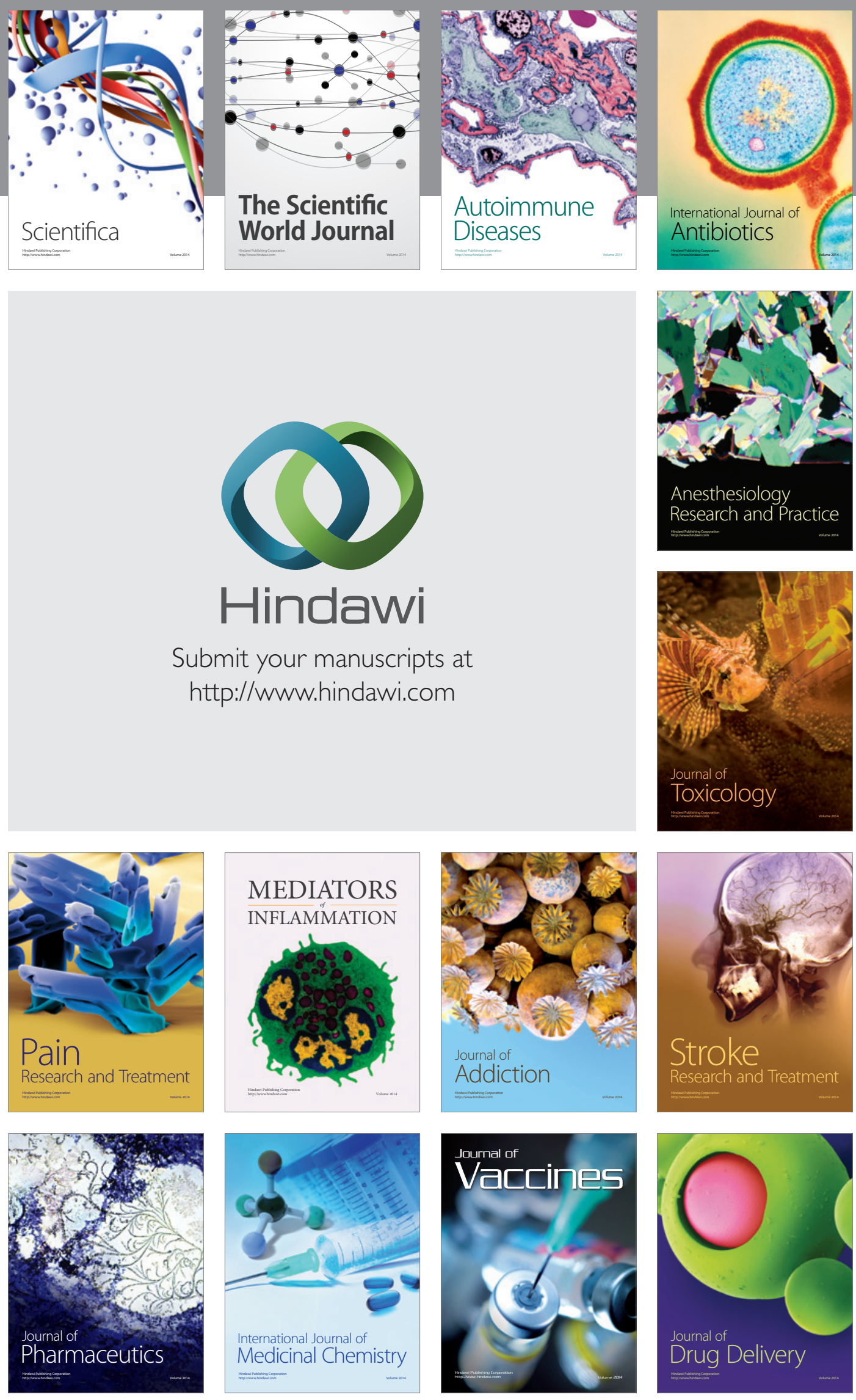